\title{
Hospitals need more guidance on implementing guidelines for the safe use of medical devices
}

Citation for published version (APA):

Porte, P. J., Meijs, J. D. M., Verweij, L. M., de Bruijne, M. C., van der Vleuten, C. P. M., \& Wagner, C. (2018). Hospitals need more guidance on implementing guidelines for the safe use of medical devices. Health Policy and Technology, 7(2), 166-172. https://doi.org/10.1016/j.hlpt.2018.02.001

Document status and date:

Published: 01/06/2018

DOI:

10.1016/j.hlpt.2018.02.001

Document Version:

Publisher's PDF, also known as Version of record

Document license:

Taverne

Please check the document version of this publication:

- A submitted manuscript is the version of the article upon submission and before peer-review. There can be important differences between the submitted version and the official published version of record.

People interested in the research are advised to contact the author for the final version of the publication, or visit the DOI to the publisher's website.

- The final author version and the galley proof are versions of the publication after peer review.

- The final published version features the final layout of the paper including the volume, issue and page numbers.

Link to publication

\footnotetext{
General rights rights.

- You may freely distribute the URL identifying the publication in the public portal. please follow below link for the End User Agreement:

www.umlib.nl/taverne-license

Take down policy

If you believe that this document breaches copyright please contact us at:

repository@maastrichtuniversity.nl

providing details and we will investigate your claim.
}

Copyright and moral rights for the publications made accessible in the public portal are retained by the authors and/or other copyright owners and it is a condition of accessing publications that users recognise and abide by the legal requirements associated with these

- Users may download and print one copy of any publication from the public portal for the purpose of private study or research.

- You may not further distribute the material or use it for any profit-making activity or commercial gain

If the publication is distributed under the terms of Article $25 \mathrm{fa}$ of the Dutch Copyright Act, indicated by the "Taverne" license above, 


\title{
Hospitals need more guidance on implementing guidelines for the safe use of medical devices
}

\author{
Petra J. Porte ${ }^{\mathrm{a}, *}$, Jill D.M. Meijs ${ }^{\mathrm{a}}$, Lisanne M. Verweij ${ }^{\mathrm{a}}$, Martine C. de Bruijne ${ }^{\mathrm{b}}$, \\ Cees P.M. van der Vleuten ${ }^{c}$, Cordula Wagner ${ }^{\mathrm{a}, \mathrm{b}}$ \\ a The Netherlands Institute for Health Services Research (NIVEL), Otterstraat 118-124, Utrecht 3513CR, The Netherlands \\ ${ }^{\mathrm{b}}$ Department of Public and Occupational Health, Amsterdam Public Health research institute (APH), VU University Medical Center, Amsterdam, The \\ Netherlands \\ ${ }^{\mathrm{c}}$ Department of Educational Development and Research, University of Maastricht, Maastricht, The Netherlands
}

\section{A R T I C L E I N F O}

\section{Article history:}

Available online 26 April 2018

\section{Keywords:}

Medical devices

Training

Implementation

Safety

\begin{abstract}
A B S T R A C T
Objectives: To gain insight into the current implementation of national guidelines on training, examination and registration of proficiencies for the safe use of medical devices and to explore the barriers and facilitators faced during the implementation of these national guidelines.

Methods: A questionnaire was sent to all Dutch hospitals and interviews were held with staff at six hospitals.

Results: There are differences between hospitals in the implementation stage, but also within hospitals. The questionnaire showed differences between training and examination for devices used by nurses and those used by medical specialists. The interviews showed that most barriers and facilitators for implementation of the national guidelines can be found in organizational factors.

Conclusions: According to the hospitals, implementation of national guidelines for the safe use of medical devices is a complex process that involves all departments. Furthermore, the staff do not always feel a sense of urgency to improve the safe use of medical devices. To facilitate implementation, more national guidance could be helpful.
\end{abstract}

(c) 2018 Fellowship of Postgraduate Medicine. Published by Elsevier Ltd. All rights reserved.

\section{Introduction}

Medical devices have become increasingly important for the diagnosis, monitoring and treatment of patients [1]. In the USA, there are an estimated 454,383 device-related adverse events a year that result in emergency department visits [2]. In the UK, the National Health Service estimates that 400 people a year die or are seriously injured in adverse events involving medical devices [3]. Given the growing numbers of medical devices coupled with the high incidence of device-related adverse events, the safe use of medical devices has become increasingly important for patient safety [4].

To improve safety, the World Health Organization (WHO) and the International Organization for Standardization (ISO) developed regulations for the safe use of medical devices $[5,6]$. The WHO developed a guide based on the regulatory systems of countries with advanced medical device regulations, including the United States, Canada, European countries, Australia and Japan. The ISO standard has been developed to assess an organization's ability to meet con-

\footnotetext{
* Corresponding author.

E-mail address: p.porte@nivel.nl (P.J. Porte).
}

sumer and regulatory requirements. The regulations of both the WHO and ISO are based on the life cycle of the medical device. This life cycle consists of the conception and development, manufacture, packaging and labelling, advertising, sale, use and disposal of the medical device [3]. Because of their focus on the full life cycle of the medical device, they lack a detailed description of appropriate use of medical devices in specific settings, such as the hospital.

In 2011, national guidelines were developed in the Netherlands to improve the safe application of medical devices in hospitals. The 'Covenant for the safe application of medical devices in hospitals' [7] was commissioned by representatives of all Dutch hospitals and aims to improve the risk management and safe application of medical devices in patient care. The covenant defines the safe application of medical devices as: 'A safe device in the hands of a trained user in a setting that can ensure safe use' [7]. These national guidelines cover three stages of the life cycle of medical devices in hospitals, namely implementation, use and disposal.

The phase in the life cycle where device-related adverse events occur is in the use of the device [8]. The UK National Patient Safety Agency reported that device-related incidents are caused by device 
failure (43.8\%), inappropriate use (29.3\%), lack of training (12.3\%) and poor maintenance (1.5\%) [9]. Both the WHO regulations and the ISO standard state that staff should have the necessary knowledge, skills and experience before they work with a device. In accordance with this, the Dutch national guidelines state: 'The hospital must have a procedure that ensures that a user who applies a medical device for the first time is proficient in the application of the medical device' [7].

The importance of making sure that users of medical devices are proficient in using that medical device is also reported in the literature. Thomas et al. reported that a meaningful proportion of device-related adverse events are caused by human error [9]. Although there are many factors that affect the likelihood of human error, some of these adverse events could be prevented by having proficient staff. Ensuring that staff are proficient in the use of medical devices is an extensive and time-consuming process [10]. Furthermore, staff members experience barriers to becoming proficient, for example in terms of time constraints, lack of support and working commitments [11]. National guidelines could help in ensuring the proficiency of staff, but little is known about the factors which could hamper (barriers) or enhance (facilitators) implementation of these guidelines.

The objective of this study was to gain insight into the current implementation of training and examination for the safe use of medical devices and to explore the barriers and facilitators faced during the implementation of the national guidelines for the safe application of medical devices. Therefore, a national survey was conducted among hospitals and interviews were held with hospital staff.

\section{Methods}

This study is a cross-sectional study with a mixed-methods design. Quantitative data were collected using a questionnaire. Interviews with hospital staff were held to study perceived barriers and facilitators during implementation.

\section{Questionnaire}

The questionnaire included questions on the extent of implementation of the national guidelines. The majority of questions addressed the proficiency of users by asking about the organization of training and examination. The questionnaire was developed based on literature and expert opinions and was discussed with researchers. The questionnaire was then tested with six members of the Medical Devices taskforce of the Dutch Hospital Association in order to achieve face and content validity. This showed that general questions concerning training, examination and registration of proficiencies were difficult to answer because of the differences between technologies and users. These questions were changed to device-specific questions for electrosurgery and infusion technology. These technologies were chosen because they are widely used, are seen as high-risk medical devices and have different main users. Infusion pumps are used to deliver fluids into a patient's body and are often operated by nurses. Because they are regularly used for critical fluids and high-risk medication, failures can have significant implications for patient safety [12]. Electrosurgery is used by surgeons to cut, coagulate, desiccate and fulgurate tissue. High-frequency current is passed through tissue to generate heat. If not properly used, this high current can injure both patient and operator [13].

Finally, the Dutch Ministry of Health, Welfare and Sport, the Dutch Hospital Association and the Netherlands Federation of University Medical Centres were consulted about the questionnaire. The questionnaire (Appendix A) started with general questions about the hospitals, followed by questions about the extent and organization of implementation. Next, questions were asked about the organization of training and examination for the use of electrosurgery and infusion technology. Finally, the questionnaire asked about the registration of proficiency among staff.

\section{Participants}

The paper-based questionnaire was sent to all 86 Dutch hospitals, both university and general hospitals, in December 2015 [14]. If a hospital had multiple locations, we selected the main location. If the main location was not clear, the questionnaire was sent to all locations. We addressed the board of directors, who were asked to send the questionnaires to the person responsible for implementation of the national guidelines in their hospital. Two reminders were sent to the non-respondents, three and four weeks after the first questionnaire. After these reminders, we phoned all non-responding hospitals to ask them to participate.

\section{Analysis}

After data was entered manually, $10 \%$ of the data were checked for accurate entry. An error rate of less than $1 \%$ incorrect data entry was considered acceptable. Data analysis was done and checked by two researchers (JM and PP). The responses to the questionnaires were analysed using descriptive statistics in Stata 14 (StataCorp, 2015). A chi-square test was used to test for significant differences between the organizations for users of infusion technology and electrosurgery. A p-value below 0.05 was considered statistically significant.

\section{Interviews}

In addition to the questionnaire, staff at six hospitals were invited for an interview. These interviews focused on implementing procedures regarding the proficiency of the staff. A semi-structured topic guide with open questions was developed based on items in the national guidelines (Appendix B). The topic guide elaborated on their experiences in general during implementation and on facilitators, barriers and how they overcame barriers.

\section{Participants}

For the interviews, we purposively selected hospitals that had been implementing the national guidelines for more than one year. These hospitals were selected to ensure they had already encountered barriers and facilitators during implementation. Hospitals were selected and approached if reports by the Healthcare Inspectorate or presentations at national congresses showed they had been implementing parts of the guidelines focusing on the proficiency of users for more than one year. Between December 2015 and January 2016, we interviewed the employees who were responsible for implementation of the national guidelines. We tried to ensure a general view instead of a device- or professionalspecific view by asking the respondents to answer the questions while keeping all types of medical devices and different professionals in mind. All interviews were conducted by a single interviewer (JM) in a private room at the workplace of the respondent.

\section{Analysis}

The interviews were recorded using a digital audio recorder and transcribed, coded and analysed using MAXQDA (MAXQDA11;VERBI Software $\mathrm{GmbH}$, Germany). For quality assurance, each participant received a written transcript of the interview. Coding was conducted by two researchers (JM and LV) using codes taken from the domains of the PRISM Framework [15]. This framework was chosen because it considers implementation in non-research settings. The framework focuses on implementation in healthcare and consists of 39 elements in four domains. These domains are: 1) elements of 
the programme (organizational and patient perspective), 2) characteristics of recipients of the programme (organizational and patient characteristics), 3) influences of the external environment and 4) implementation and sustainability infrastructure. Because the implementation has an influence on professionals, we chose to use the professional perspective and characteristics instead of the patient perspective and characteristics. The coding by the two researchers was discussed until consensus was reached. Hereafter, the coding was used to establish connections between themes and to identify the essence of each theme. Finally, two researchers (PP and LV) discussed the themes that emerged from the analysis and possible explanations for these findings.

\section{Results}

\section{Questionnaire}

\section{Participants}

The questionnaire was sent to all 86 general and university hospitals in the Netherlands. Six hospitals had recently merged. Of the 80 remaining hospitals, 65 hospitals returned the questionnaire ( $81 \%$ response rate). Nine hospitals were not able to participate in this study due to time constraints, three hospitals did not provide a reason for non-participation and in three hospitals the responsible employee could not be reached. 26 out of 65 respondents were medical physicists and nine respondents were heads of the medical devices department. The median number of beds in the hospitals was 497 (interquartile range 300-750). The number of responses to a question can deviate from the total number of respondents because hospitals were asked to skip questions if professionals did not receive regular training.

\section{General implementation of the national guidelines}

Almost all hospitals (95\%) have a multidisciplinary taskforce that is responsible for the implementation of the proficiency part of the national guidelines. The group generally includes the head of the medical devices department, a medical specialist, a medical physicist, a policy officer and an educational expert. The biggest cluster of hospitals (30\%) started the implementation of the national guidelines after a letter from the Healthcare Inspectorate in June 2015, which announced the inspectorate would start auditing the implementation in January 2016. The hospitals are at different stages in the implementation of the national guidelines, ranging between adoption (28\%), implementation (40\%) and evaluation and maintenance (32\%). Hospitals that are in the adoption stage have an action plan or protocols that are in line with the national guidelines. If hospitals are in the implementation stage, this means these protocols are being followed. In the evaluation and maintenance stage, the protocols are being adapted based on evaluation of the implementation.

\section{Proficiency of users}

Questions about examination and the registration of the proficiency of users were asked separately for two technologies: infusion technology and electrosurgery. Users of infusion technology were more likely to have been trained $(p<0.001)$ and examined $(p<0.001)$ and the proficiencies were also more likely to be monitored $(p<0.001)$. Lack of proficiency is more likely to be revealed during an annual assessment interview in the case of infusion technology $(p<0.001)$ and because of a mistake or complication in the case of electrosurgery $(p=0.024)$. The main results for the questions about proficiency are presented in Fig. 1. Training in infusion technology was more often a combination of knowledge and skills (67\% of the training programmes) in comparison with training in electrosurgery, which mostly involves training in skills only ( $48 \%$ of the training programmes). In $69 \%$ of hospitals, the type of training and examination medical specialists receive for other high-risk medical devices is similar to a high or very high degree to the training and examination in electrosurgery. In $75 \%$ of hospitals, the training and examination nurses receive for other high-risk medical devices is similar to a high or very high degree to the training and examination in infusion technology.

\section{Interviews}

\section{Participants}

The interviews were performed with nine employees in total, at six hospitals, who were responsible for implementation of the parts of the national guidelines that concerned the proficiency of staff. No new information emerged in the fifth and sixth interviews, which implied that data saturation had been reached. Four of the interviewees were medical physicists, four worked in the educational department and one was the head of the medical device department. The interviews ended when all information had been collected and took between 27 and 89 minutes (mean length 59 minutes). Most interviewees were male (6 out of 9 ). The interviews were held in hospitals of different sizes and types (two university and four general hospitals). The stage of implementation in the hospitals where interviews were held varied between adoption and evaluation and maintenance. All six hospitals had developed a programme for the training of staff, although sometimes this plan indicated that no training was needed for medical specialists. The main results of the interviews are displayed in Fig. 2 and explained below.

\section{Organizational perspective}

Respondents perceived "readiness", "addressing the barriers facing frontline staff" and "coordination across departments" as both barriers and facilitators. "Strength of the evidence" in relation to patient safety and "burden" were seen as barriers for implementation of the national guidelines. Respondents remarked in particular on the reasons that medical specialists gave for the implementation being a burden.

One reason the medical specialists mentioned was the amount of additional work in combination with their already high workload. Another reason according to medical specialists was that the national guidelines reduced their autonomy. However, the readiness for implementation can be triggered by an incident or by external pressure such as an audit by the Healthcare Inspectorate, which is a governmental healthcare supervisory authority.

"I think that the problem is that you ask things from people who are close to being overloaded. The drawback is that you encounter autonomy questions." (Respondent 3)

"But people are only going to really do things when there is pressure. And that pressure comes from a major incident or if the inspectorate breathes down your neck." (Respondent 6)

For this reason, respondents stated that the barriers faced by frontline staff should be addressed. A perceived barrier is that departments spend as little time as possible on the development of training. These barriers could be reduced by respecting and helping the frontline staff and by adjusting the level of training to the level of the employee. Another facilitator is tempting employees into training by making it an enjoyable activity.

"It is about tempting professionals to get trained. That sounds a bit odd, but professionals are rather afraid of training and exams. But it can be made enjoyable if an appealing speaker is invited, if 


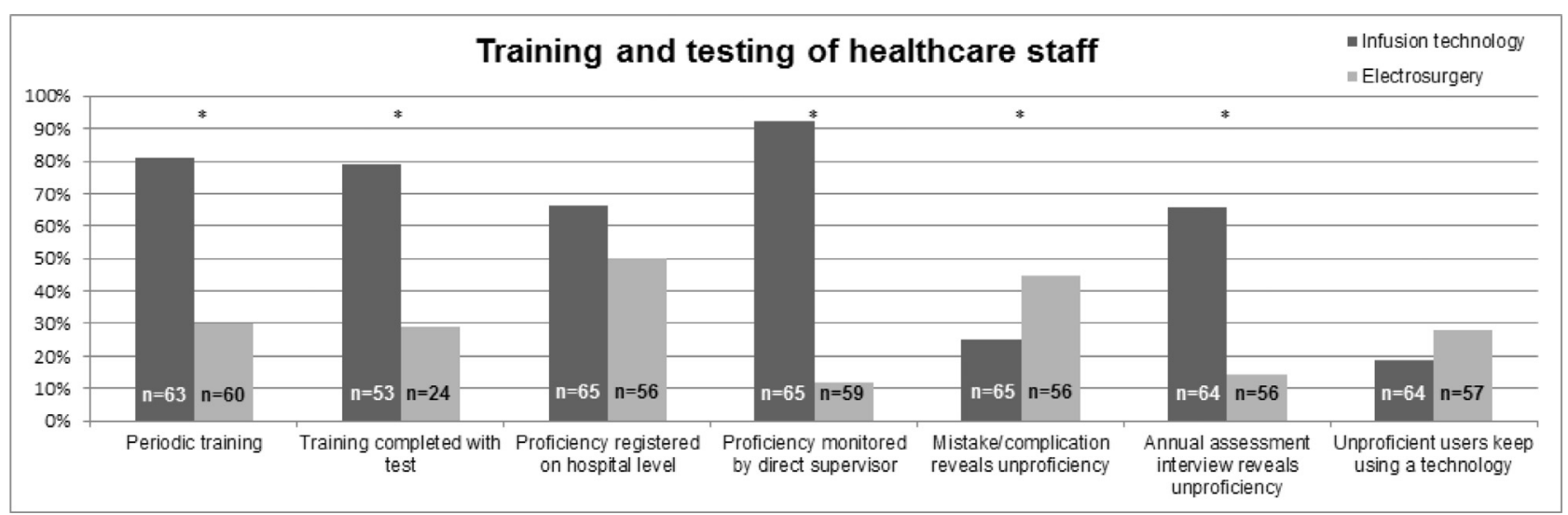

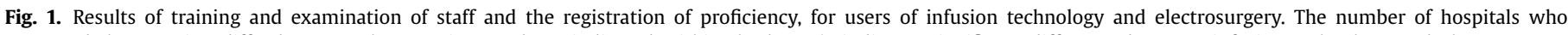

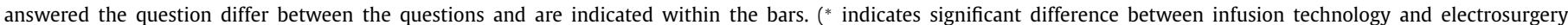
$(P<0.05))$.

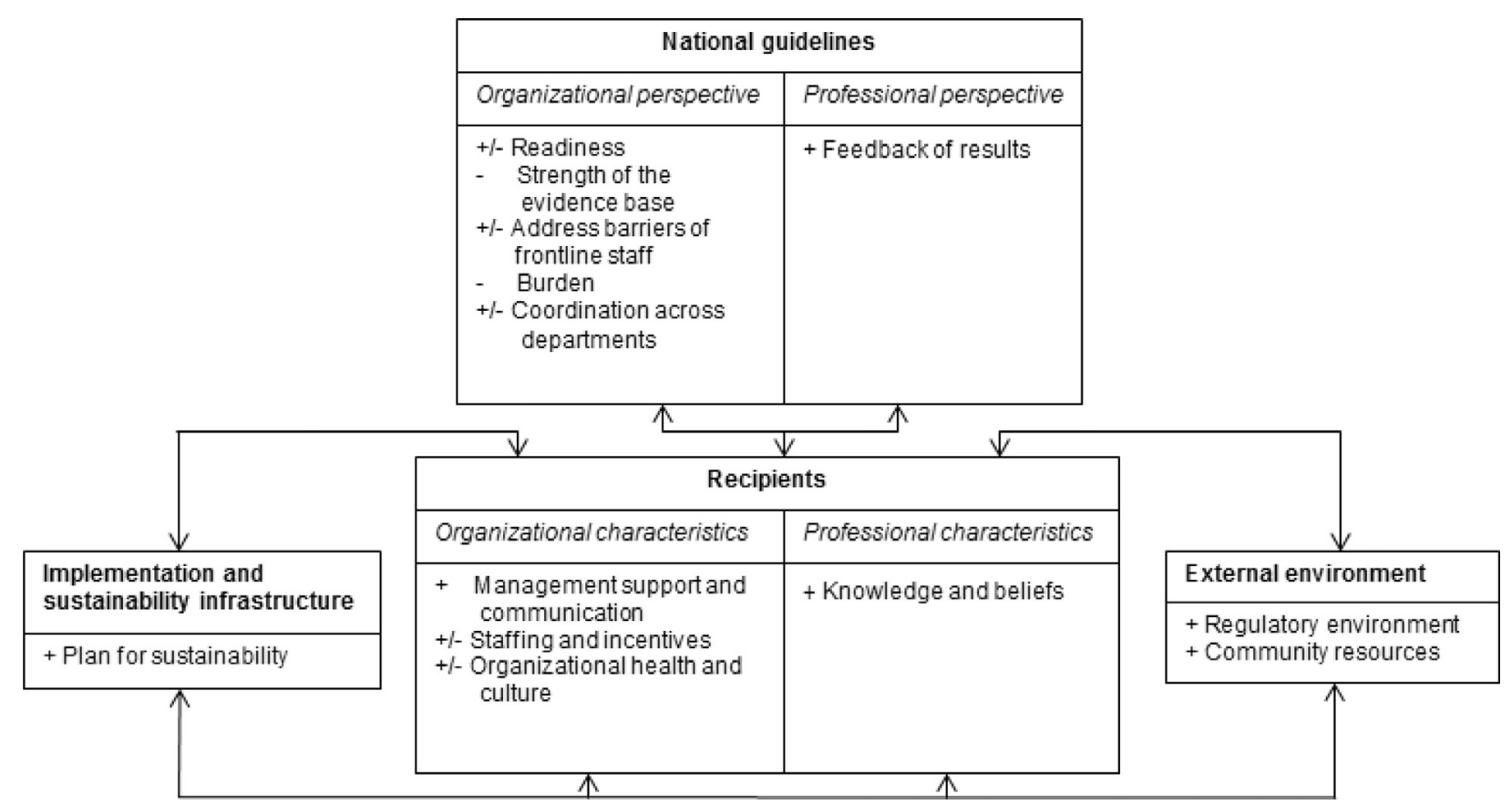

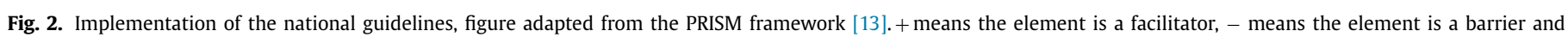
$+/-$ means the element is both a barrier and facilitator for implementation.

food is provided or if professionals can earn accreditation points." (Respondent 4)

Moreover, respondents perceive the strength of the evidence as a weak point. There is no evidence that implementation of the national guidelines will improve safety, and similar programmes did not prove to be effective.

"Hospitals often cover their bases because the Healthcare Inspectorate wants it. So we can measure everything objectively, all very formal, yet the effect has been shown to be small." (Respondent 3)

The burden is seen as an important barrier by the respondents. Elements that are named as barriers are the large amount of time it takes to implement the national guidelines, the complexity of the implementation and the amount of money needed for the development of training.

Another factor is the hospital-wide nature of the national guidelines, which makes coordination across departments necessary, according to respondents. The respondents see the involvement of different departments as a barrier. A positive aspect in the experience of the respondents is the formation of connections between the different departments.

"The hospital has to deal with the covenant [national guidelines] and that affects everyone. They looked at why some hospitals manage it and others don't. You need someone who can connect people." (Respondent 4) 


\section{Organizational characteristics}

"Management support" and "communication" are facilitators according to the respondents, while "staffing and incentives" and "organizational health and culture" are seen as both barriers and facilitators.

Respondents say implementation is facilitated if the management makes implementation a priority, actively promotes implementation and has a strict policy.

"Can you name a facilitator in this hospital?" (interviewer) "Initially, the strict policy of the board of directors. No longer accepting that people are not proficient." (Respondent 5)

Management also has an influence on the organizational health and culture. The organization is both a barrier and a facilitator. Respondents named giving feedback and a culture in which staff can give each other criticism as a facilitator. However, high turnover in staff is seen as a barrier that might influence the existing culture and knowledge.

"We must make people aware of how to work with devices and teach them that you need to work safely with people. It is much more about creating a culture within the organization in which learning is normal." (Respondent 2)

Furthermore, respondents mentioned the personal responsibility of staff for their own proficiency as both a barrier and a facilitator. Staff appreciate it when they are trusted to judge their own level of proficiency. A barrier is that staff are not always motivated to work on their proficiency.

\section{Professional perspective and characteristics}

"Feedback of results" from training and examination is seen as a facilitator. Feedback encourages staff to attend training. Staff are also encouraged if there is a positive incentive, for example accreditation points when they complete a training programme.

Moreover, respondents perceive the knowledge and beliefs of staff as a facilitator for implementation. It helps if staff have an intrinsic motivation to be proficient and to attend training.

\section{Implementation and sustainability infrastructure}

A facilitator for the implementation of the national guidelines is the "existence of a plan for sustainability". Respondents mentioned a continuous cycle of improvement and recurrent audits or evaluations as facilitators.

"I see that it is a project in many hospitals. We do it and then it's finished, whereas it is actually a permanent notion. It is also not a question of getting it right in one go, because next year we have another cycle and we have new people etc. You have to continuously keep doing that (updating risk analysis and quality documents]." (Respondent 4)

\section{External environment}

The "external environment" can have a facilitating effect on the implementation of the national guidelines. Facilitators are having the process steered at the national level and determining nationally which technologies cause a large number of adverse events.

"What also plays a role is that we had very few really testable standards. For electrosurgery there is a list from the association with standards for knowledge requirements. That harmonizes what people need to know, and that was what was missing. We see that it is starting to take off now." (Respondent 3)

\section{Discussion}

The objective of this study was to gain insight into the current implementation of national guidelines on training and examination for the safe use of medical technologies and the barriers and facilitators during implementation of the guidelines. The stage that hospitals had reached in the implementation of the national guidelines varied between adoption (28\%), implementation (40\%) and maintenance (32\%). Furthermore, the questionnaire data showed differences in training and examination between two different devices with different main users. The interviews showed that most barriers and facilitators of implementation of the national guidelines can be found in the organizational factors, like readiness, strength of the evidence base and addressing barriers experienced by frontline staff. Facilitators for implementation are the knowledge and beliefs of staff, giving staff feedback, a plan for sustainability and external resources.

\section{Differences between medical devices in procedures}

Procedures regarding the examination and registration of the proficiency of users are more likely to be applied for users of infusion technology in comparison with users of electrosurgery. A likely explanation is the difference in the main users: infusion technology is used by nurses while electrosurgery is used by medical specialists. More barriers are perceived by respondents when training and examining medical specialists in comparison with nurses. Respondents mention that the autonomy and workload of medical specialists could explain why implementation is more difficult. Previous studies have shown that resistance to change is mainly high in professions characterized by professional autonomy $[16,17]$. Moreover, resistance to change is also known to increase when the workload is higher [18]. The increase in resistance is caused by the fear or knowledge that change requires an investment of time. Another explanation could be that nurses are more used to being examined. Implementation of new processes is easier when changes are smaller and new procedures are in line with old procedures [19]. However, it is unclear whether hospitals do not try to implement training and examination or whether they try but do not manage to implement it. The interviews indicated that more barriers were perceived with the training and examination of medical specialists. Moreover, the questionnaire data showed there were different policies for nurses and medical specialists. This could indicate that hospitals do not try to implement training and examination for certain types of users.

\section{Barriers and facilitators for implementation}

The interviews gave insight into the barriers and facilitators for implementation. We found that the implementation of the national guidelines is a complex process with barriers and facilitators from several different origins. Most barriers and facilitators can be found in the organizational perspective and characteristics. This project involves all the different departments and layers of the organization. The costs and time the implementation takes are seen as an important barrier. There are not enough staff and money available to facilitate the implementation. This problem is often seen in hospitals as a barrier to implementation [18,20]. National support from experts or frameworks to guide implementation could help hospitals with the implementation. Moreover, a factor that increases the burden is that people do not see the importance and extent of the problem [20]. Most staff within the hospital see the implementation of the national guidelines as a problem, while the real problem is the unsafe use of medical devices and the effects this has on patient safety. Although this subject is receiving increased attention, the interviews suggest that hospitals still need 
an incident or visit from the Healthcare Inspectorate to make the safe use of medical devices a priority.

Accordingly, respondents say the management has important facilitating effects. The first facilitator is the promotion of the national guidelines. Promotion makes staff aware of the existence and importance of the implementation [20]. In addition, it is helpful if the management has a strict policy. If management clearly considers implementation to have a high priority, staff are motivated to implement the national guidelines. Moreover, creating a culture in which training, examination and registration of proficiency is normal could facilitate implementation, although it is important not to demotivate staff by giving them an increased workload. However, staff also have to perceive the importance of being proficient and should no longer think it is acceptable to use medical devices in which they are not proficient. The current organizational culture regarding the proficiency of staff can be both a barrier and a facilitator. Some facilitators for involving staff in training are to tempt them with enjoyable activities and rewards. It can also help to create a culture in which giving and receiving feedback is normal. Giving and receiving feedback improves the quality of work and makes feedback in other forms, like an examination, less threatening [21]. These necessary changes in culture take time and the implementation of the national guidelines should be in line with the change in the culture.

In addition to the change in culture, a cyclical implementation of the national guidelines facilitates the sustainability and ensures a more solid implementation because the changes in the organization and environment are taken into account [22]. To ensure support among staff, it is also necessary to have proof of the positive effects of the national guidelines [17,22]. These advantages could be made visible by evaluation and improvement of the procedures. Another way to facilitate implementation is to make national frameworks available for implementation. These frameworks could describe in more detail which steps should be taken for a solid implementation and could for example give expert opinions about the organization of training and examination of proficiencies. These frameworks should not be forced upon hospitals but could help them determine the right procedures.

\section{Strengths and limitations}

The strengths of this study are the high response rate of $81 \%$ and the mixed methods design. The content and face validity of the questionnaire was assured by consulting several experts. A general limitation in survey research is the risk of social desirable answers of respondents. In this case, respondents involved in the implementation of the guidelines could have given more positive answers than other respondents. This potential bias is minimized by collecting data in a confidential way and assuring that all results are treated confidentially. The hospital respondents answered most questions, including the confidential ones, minimizing the chance that respondents deliberately did not answer questions. Another limitation of this study is that it was conducted in the Netherlands, which might influence the generalizability of the findings. Although there are few countries with guidelines for the safe use of medical devices, this is a subject of growing importance and interest. Countries that decide to implement similar guidelines could use this study to facilitate the implementation. Furthermore, the questionnaire focused on two types of medical devices, which might also influence generalizability. On the other hand, staff indicated in the questionnaire that training and examination are similar for other high-risk medical devices.

\section{Conclusions}

This study shows that the implementation of a national guideline for the safe application of medical devices is a complex process in which all the different departments in a hospital are involved. An instigator such as an incident or external pressure facilitates implementation. This could indicate that staff do not always experience a sense of urgency for the proficient use of medical devices amongst other priorities. Moreover, differences were found between the training and examination of nurses and that of medical specialists. A better understanding of the reasons for this difference could reveal other barriers and facilitators of implementation. Another barrier is the lack of staff, time and money. For this, national guidance, for example through frameworks or expert opinions, could be helpful to facilitate the implementation of national guidelines.

\section{Author Statements \\ Funding}

The authors received funding from the Dutch ministry of Health, Welfare and Sport to support the research. The ministry in no way influenced the study design or interpretation of results.

\section{Competing interests}

None declared.

\section{Ethical approval}

Not required.

\section{Supplementary materials}

Supplementary material associated with this article can be found, in the online version, at doi:10.1016/j.hlpt.2018.02.001.

\section{References}

[1] KNAW. Evaluation of new technology in health care. In need of guidance for relevant evidence. Amsterdam: KNAW; 2014

[2] Hefflin BJ, Gross TP, Schroeder TJ. Estimates of medical device-associated adverse events from emergency departments. Am J Prev Med 2004;27:246-53.

[3] An organisation with a memory. London: National Health Service; 2000.

[4] Godycki-Cwirko M, Esmail A, Dovey S, Wensing M, Parker D, Kowalczyk A et al. Patient safety initiatives in Central and Eastern Europe: a mixed methods approach by the LINNEAUS collaboration on patient safety in primary care. Eur J Gen Pract 2015;21(Suppl):62-8.

[5] Medical device regulations: global overview and guiding principles. World Health Organization; 2003.

[6] Medical devices - Quality management systems - Requirements for regulatory purposes (13485:2016(E)). Switzerland: ISO; 2016.

[7] Convenant veilige toepassing van medische technologie in de medisch specialistische zorg. Nederlandse Vereniging van Ziekenhuizen(NVZ), Nederlandse Federatie van Universitair Medische Centra(NFU), Revalidatie Nederland(RN) en Zelfstandige Klinieken Nederland(ZKN); 2016.

[8] Wagner U. Risks in application of medical devices: human factors in the medical environment. Qual Manag Health Care 2010;19:304-11.

[9] Thomas AN, Galvin I. Patient safety incidents associated with equipment in critical care: a review of reports to the UK National Patient Safety Agency. Anaesthesia 2008;63(11):1193-7.

[10] Gullikson ML, David Y, Blair CA. The role of quantifiable risk factors in a medical technology management program. EC/PTSM series; 1996. No. 3.

[11] Shahhosseini Z, Hamzehgardeshi Z. The facilitators and barriers to nurses' participation in continuing education programs: a mixed method explanatory sequential study. Glob J Health Sci 2014;7(3):184-93.

[12] Administration USFD. Infusion Pumps https://www.fda.gov/MedicalDevices/ ProductsandMedicalProcedures/GeneralHospitalDevicesandSupplies/ InfusionPumps/default.htm.

[13] Cordero I. Electrosurgical units - how they work and how to use them safely. Commun Eye Health J 2015;28(89):15-16.

[14] RIVM. Nationale Atlas Volksgezondheid [Locations General and Academic Hospitals]. Available from: http://www.zorgatlas.nl/zorg/ziekenhuiszorg/. 
[15] Feldstein AC, Glasgow RE. A practical, robust implementation and sustainability model (PRISM) for integrating research findings into practice. Joint Commission J Qual Patient Saf 2008;34(4):228-43.

[16] Michie S, Johnston M, Abraham C, Lawton R, Parker D, Walker A, et al. Making psychological theory useful for implementing evidence based practice: a consensus approach. Qual Saf Health Care 2005;14(1):26-33.

[17] Hakkennes S, Dodd K. Guideline implementation in allied health professions: a systematic review of the literature. Qual Saf Health Care 2008;17(4):296300.

[18] Bergs J, Lambrechts F, Simons P, Vlayen A, Marneffe W, Hellings J, et al. Barriers and facilitators related to the implementation of surgical safety checklists: a systematic review of the qualitative evidence. BMJ Qual Saf 2015;24(12):776-86.
[19] Gagnon MP, Nsangou ER, Payne-Gagnon J, Grenier S, Sicotte C. Barriers and facilitators to implementing electronic prescription: a systematic review of user groups' perceptions. J Am Med Inform Assoc 2014;21(3):535-41.

[20] McAlearney AS, Walker DM, Livaudais-Toman J, Parides M, Bickell NA. Challenges of implementation and implementation research: learning from an intervention study designed to improve tumor registry reporting. SAGE Open Med 2016;4:2050312116666215.

[21] Veloski J, Boex JR, Grasberger MJ, Evans A, Wolfson DB. Systematic review of the literature on assessment, feedback and physicians' clinical performance: BEME Guide No. 7. Med Teach 2006;28(2):117-28.

[22] A guide to the development, implementation and evaluation of clinical practice guidelines. Australia: National Health and Medical Research Council; 1998. 